\title{
Framing responsibility (Health Coverage)
}

\section{AUTHOR}

Doreen Reifegerste, Annemarie Wiedicke

\section{KEYWORDS}

framing, responsibility framing, media frames, attribution theory

\section{BRIEF DESCRIPTION}

Responsibility frames in media coverage describe the mediated attribution of responsibility for causes and remedies (treatments, solutions) for health issues, mostly differentiating between individual and societal responsibility.

FIELD OF APPLICATION/THEORETICAL FOUNDATION Media coverage of health topics, public opinion formation, attribution of responsibility, framing studies, social media on health issues

\section{EXAMPLE STUDIES:}

Gollust \& Lantz (2009); Kim \& Willis (2007); O’Hara \& Smith (2007); Stefanik-Sidener (2013); Yoo \& Kim (2012); Zhang \& Jin (2015)

\section{INFORMATION ON KIM \& WILLIS, 2007}

Authors: Sei-Hill Kim, Leigh Anne Willis Health topic: Obesity

Research questions: How have the media presented the causes and solutions for obesity? Have certain causes and solutions appeared more often than others? How has media coverage of causal and solution responsibility changed over the years? Have mentions of certain causes and solutions increased or decreased?

Object of analysis: Newspaper and television news data containing "obesity" or "obese" appearing in the headline, lead paragraphs, or index terms; articles published in The New York Times, The Washington Post, Chicago Sun-Times, The
San Francisco Chronicle, The Houston Chronicle, and USA Today; news transcripts on obesity from three television networks (ABC, CBS, NBC); after conducting a systematic sampling, $\mathrm{n}=300$ articles and $n=200$ transcripts were analyzed Time frame of analysis: January 1995 to August 2004

\section{INFO ABOUT VARIABLES}

Variables: Variables included attributions of causal and treatment responsibility, cause or treatment option was coded as "not present" (0) or "present" (1).

Level of analysis: News article respectively tv transcript

see Table 1

\section{INFORMATION ON STEFANIK-SIDENER, 2013}

Author: Kelsey Stefanik-Sidener

Health topic: Diabetes

Research questions: What was the dominant frame used in news stories about diabetes? What were the most common cause and solution frames used for each type of diabetes?

Object of analysis: Diabetes coverage in the New York Times $(\mathrm{N}=239)$

Time frame of analysis: 2000 to 2010

\section{INFO ABOUT VARIABLES}

Variables: The articles were coded for the presence of three types of frames for both causes of and solutions to diabetes, respectively: behavioral, societal, or medical, frames were not mutually exclusive

Level of analysis: News article see Table 2 


\section{Table 1.}

Causal responsibility

\section{Personal causes $($ Scott's $\mathbf{p i}=\mathbf{~ . 8 1})$}

Unhealthy diet: Consuming too much food, consuming too much unhealthy food, addictive or emotional eating. Sedentary lifestyle: Lack of exercise, Lack of physical activities.

Genetic conditions: Genetic=biological factors that may produce obesity (e.g., imbalance of hunger hormones that may stimulate appetite).

Others: E.g., poor adult role models.

\section{Societal causes $($ Scott's $\mathbf{p i}=\mathbf{~ . 8 6})$}

The food industry: Obesity-promoting foods (fast=junk food), super-sizing, large increase in fast=junk food restaurants, other aggressive marketing promotions.

Schools \& education: Unhealthy foods in school cafeterias, lack of physical activity programs at schools, lack of public education about healthy eating and lifestyle.

Socioeconomic factors: Low-income families may not be able to afford healthy food, exercise equipment, or a gym membership. They may be too busy to prepare their own healthy food.

Others: E.g., automobile-oriented society (e.g., drive-thru stores and restaurants, big-box stores), unsafe community (crime, traffic, accident), and limited opportunities for outdoor activities.

\section{Solution responsibility}

\section{Personal solutions (Scott's $\mathbf{p i}=\mathbf{. 7 4}$ )}

Healthy diet: Consuming less food, consuming healthy food.

Physically activities: More exercise and physical activities.

Medical treatments: Medications (e.g., diet pills), surgical treatments of obesity (e.g., gastric bypass, gastric stapling).

Others: E.g., working with a support group, talking to a counselor, parents as role models.

\section{Societal solutions (Scott's $\mathbf{p i}=\mathbf{~ . 8 1 )}$}

Regulations of the food industry: Regulating obesity-promoting foods, super-sizing, vending machines, and other aggressive marketing promotions, taxing unhealthy food.

Changes in schools \& education: Healthier food in school cafeteria, more physical activity programs at schools, more public education. Socioeconomic changes: Narrowing income gap, healthy food should be more affordable and available, more affordable exercise. Others: E.g., less automobile-oriented and more walking-oriented society (less drivethru stores and restaurants, less big-box stores), safer community, and more opportunities for outdoor activities. 
Table 2.

General cause frame (Krippendorff's Alpha= .96)

Behavioral causal frame

Poor diet, lack of physical activity, or other individual-level issues

\section{Societal cause frames}

Poor food environments, car-centered culture, poor nutrition in schools, or other broad problems

\section{Medical cause frames}

Family history, genetics, age
General solution frame (Krippendorff's Alpha= .64)

\section{Personal solutions}

Improving one's diet or increasing activity levels

\section{Societal solution frames}

Improving access to healthy foods, increasing nutrition education, or other public policy/ societal-level solutions

Medical solution frames

Blood sugar control, medication, or surgery

\section{INFORMATION ON YOO \& KIM, 2012}

Authors: Jina H. Yoo, Junghyun Kim

Health topic: obesity

Research questions: What typifications (i.e., causal claims and solution claims) have been made in videos on YouTube with regard to the obesity issue? How do these typifications vary among different types of media formats on YouTube?

Object of analysis: YouTube was searched with the keywords "obesity" and "obese" on 5 March 2010 and owing to capacity limits, the number of available videos was limited to 1,000 per each keyword; after a systematic random sampling and excluding irrelevant videos, total sample of $\mathrm{N}=417$ YouTube videos was analyzed

Time frame of analysis: 2000 to 2010

\section{INFO ABOUT VARIABLES}

Variables: articles were coded for the presence of causal claims and solution typifications, behavioral, biological, and systematic causal factors on obesity being causal claims and behavioral solution, medical or pharmacological solution and systematic solution

Reliability: Intercoder reliability was calculated for each category, and average intercoder reliability coefficient was .89 . The Cohen's kappa coefficient for each variable ranged between .77 and 1.00 Level of analysis: each whole video, including all of the video's visual, audio, and text presentation see Table 3 
Table 3.

Causal claims for obesity

Behavioral causal claim

Obesity is due to the individual's lifestyle choices, including lack of exercise, wrong diet, lack of willpower and self-control, etc.

\section{Biological causal claim}

Obesity is due to genetic or hormonal problems

\section{Systematic causal claim}

Obesity is based on environmental influences and policy choices, including detrimental practices of corporations and government, such as the fast food industry's marketing practices, school cafeterias' unhealthy foods, inadequate or inaccurate information about food and nutrition, etc.
Solution typifications for obesity

\section{Behavioral solution}

Improving one's diet or increasing activity levels

\section{Medical or pharmacological solution}

To use diet pills or have a gastric bypass surgery as a means of treating obesity.

\section{Systematic solution}

A societal level of obesity treatment, such as implementing obesity-related policies, banning fast food marketing, removing vending machines from school, etc.
INFORMATION ON ZHANG \& JIN, 2015

Authors: Yuan Zhang, Yan Jin

Health topic: Depression

Research question: Do cultural values and organizational restraints shape the responsibility frames for health issues?

Object of analysis: US $(n=228)$ and Chinese $(n=$ 224) newspaper coverage on depression, including New York Times and USA Today, Philadelphia Inquirer, Houston Chronicle, Star Tribune and Denver Post; Chinese newspapers were not further specified, except for People's Daily and Beijing Daily

Time frame of analysis: 2000 to 2012

\section{INFO ABOUT VARIABLES}

Variables: News framing of causal and problemsolving responsibilities was measured at individual and societal levels, with individual-level and society-level causes and solutions. Each cause and solution included four subcategories which were measured nominally as 0 (absent) or 1 (present).

Reliability: For the US data, a pretest in which two coders both coded a randomly selected $10 \%$ of the sample yielded Pearson's r of $0.737(p<0.001)$ for individual causes, $0.862(p<0.001)$ for socie- tal causes, $0.790(\mathrm{p}<0.001)$ for individual solutions, and $0.907(\mathrm{p}<0.001)$ for societal solutions. For the Chinese data, a pretest in which two bilingual coders both coded a randomly selected $10 \%$ of the sample yielded Pearson's r of 0.861 ( $\mathrm{p}$ $<0.001$ ) for individual causes, 0.893 ( $\mathrm{p}<0.001$ ) for societal causes, $0.807(\mathrm{p}<0.001)$ for individual solutions, and $0.899(\mathrm{p}<0.001)$

Level of analysis: Article

Variables \& operational definitions: In the appendix

\section{REFERENCES}

Gollust, S. E., \& Lantz, P. M. (2009). Communicating population health: Print news media coverage of type 2 diabetes. Social Science \& Medicine (1982), 69(7), 1091-1098. https:// doi.org/10.1016/j.socscimed.2009.07.009

Kim, S.-H., \& Willis, A. (2007). Talking about obesity: News framing of who is responsible for causing and fixing the problem. Journal of Health Communication, 12(4), 359-376. https://doi.org/10.1080/10810730701326051

O’Hara, S. K., \& Smith, K. C. (2007). Presentation of eating disorders in the news media: What are the implications for patient diagnosis and treatment? Patient 
Education and Counseling, 68(1), 43-51.

https://doi.org/10.1016/j.pec.2007.04.006

Stefanik-Sidener, K. (2013). Nature, nurture, or that fast food hamburger: Media framing of diabetes in the New York Times from 2000 to 2010. Health Communication, 28(4), 351-358. https://doi.org/10.1080/10410236.2012.688187

Yoo, J. H., \& Kim, J. (2012). Obesity in the new media: a content analysis of obesity videos on YouTube. Health Communication, 27(1), 86-97. https://doi. org/10.1080/10410236.2011.569003

Zhang, Y., \& Jin, Y. (2015). Who's responsible for depression? The Journal of International Communication, 21(2), 204-225. https:// doi.org/10.1080/13216597.2015.1052532

Zhang, Y., \& Jin, Y. (2015). Who's responsible for depression? Journal of International Communication, 21(2), 204-225. 